\title{
Retrospective analysis of Pulmonary Surfactant on Respiratory Distress Syndrome of Late Premature or Full-term Infants Paper Title
}

\author{
Hui $\mathrm{Wu}^{\mathrm{a}}$,Jing Cui ${ }^{\mathrm{b}}$, Dan Dang ${ }^{\mathrm{c}}$ \\ Department of Neonatology \\ The First Hospital of Jilin University \\ Changchun, China \\ e-mail:a wuhui97@126.com, b cuijing_1029@163.com, \\ c695344998@qq.com,
}

\begin{abstract}
This retrospective analysis evaluates the effcacy of pulmonary surfactant in respiratory distress syndrome treatment of late premature or trem infants. We compared infants receiving Curosurf pig pulmonary surfactant (PS group $n=89$ ) with those infants who didn't (control group $n=77)$. Both were treated with routine treatment and mechanical ventilation. The highest oxygenation indexes in PS group were obviously higher than those in control group $(P<0.001)$, The time of hospital stay, Mechanical ventilation and CPAP, the incidence of Ventilator-associated pneumonia and hospitalization expenses of PS group were obviously higher than that in control group $(P<0.05)$.There were no significant differences about NO inhalation, the incidence of pulmonar $>0.05$ ). PS should be applied for late premature and full-term RDS patients in the early stage, and clinical studies on PS treatment of late premature infants or full-term infants for the best medication time and optimal dosage should be further explored.
\end{abstract}

Keywords- Respiratory distress syndrome; late premature Infants; pulmonary surfactant

\section{INTRODUCTION}

Respiratory distress syndrome (RDS) is a common disease in the neonatal period, especially for premature infants. It refers to a series of respiratory symptoms resulted from pulmonary surfactant (PS) deficiency, which is caused by many reasons. Its clinical manifestations are progressive dyspnea and respiratory failure soon after birth, and the mortality is high. RDS is one of the main reasons for the death of premature infants. Abundant clinical researches[1-5] proved that PS has a positive effect on RDS prevention and treatment of early premature infants. PS replacement therapy can alleviate the symptoms, shortened the course of disease, improve the prognosis, and increase the cure rate. Besides, appling early and repeatedly, the use of mechanical ventilation and incidence of complication can be reduced. The morbidity of RDS of late premature infants and term infants has increased gradually in the past few years. However, its clinical manifestation and reaction to PS treatment are different from RDS of early premature infants. Therefore, there is still no consensus on whether PS could be used to treat RDS of late premature infants and term infants. Retrospective analysis of the clinical data of RDS of late premature infants or term infants received and cured in neonatal department of our hospital from 2006 to 2010 is carried out to evaluate the effect of PS.

\author{
Dongxuan Wang \\ Department of Ultrasonic Diagnosis \\ The First Hospital of Jilin University \\ Changchun, China \\ dongxuanwang@hotmail.com \\ ${ }^{*}$ Corresponding author : Dongxuan Wang
}

\section{METHOD}

\section{A. Participates}

166 neonates, whose gestational ages are over 34 weeks diagnosed as patients of RDS according to the diagnostic criteria [6] of Practice of Neonatology, are recruited in the neonatal intensive care unit (NICU) of The First Hospital of Jilin University from Jan. 1st, 2006 to Jan. 1st, 2010. Inclusion criteria: (1) Gestational age $\geq 34 \mathrm{~W}$; (2) Acute onset; respiratory distress appears within 72 hours after the birth of neonate; oxygen therapy is invalid and mechanical ventilation is needed; (3) Two of the following five clinical symptoms must appear: a. Respiratory rate $\geq 60$ /min.; b. Central cyanosis; c. Nasal flaring; d. Positive three depression sign; e. Expiratory groan; (4) Typical symptoms of X-rays: declining of transmittance of lungs, reticular or granular shadows, air bronchogram or even "white lung". Exclusion criteria: (1) Congenital heart disease; (2) pulmonary air leak; (3) Respiratory distress caused by extrapulmonary diseases. Eighty-nine neonates are treated with PS for at least once, while other seventy-seven neonates without PS-treatment (Pulmonary Surfactant, Curosurf) are in control group .

\section{B. Clinical outcomes}

(1) Primary outcome: mortality within 28 days after birth; (2) Secondary outcomes: (1) Respiratory support time: including mechanical ventilation, CPAP, nasal oxygen; (2) Nitrogen monoxide treatment; (3) Highest oxygenation index(OI):OI= $\mathrm{FiO}_{2}(\%) \times \mathrm{MAP}\left(\mathrm{cm} \mathrm{H}_{2} \mathrm{O}\right) / \mathrm{PaO} 2(\mathrm{mmHg})$; (4) Complications: pulmonary air leak, pulmonary hypertension, ventilator-associated pneumonia(VAP), pulmonary hemorrhage; (5) Length of hospital stay; (6) Hospitalization expenses.

\section{Statistic method}

SPSS16.0 software is used for statistical analysis. Measurement data: length of hospital stay, hospitalization expenses, duration of oxygen supplementation, time of PS application, gestational age and birth weight all do not conform to the normal distribution, which is represented by median (interquartile range) and Spearman rank sum test is applied. Enumeration data: $\chi^{2}$ test is used for comparison 
between the two groups. $\mathrm{P}<0.05$ was considered to be significant.

\section{RESULTS}

\section{A. Clinical characteristics of infants in the PS group $(n=89)$ or placebo $(n=77)$ groups}

There is no statistical difference in gestational age, gender, birth parity, birth weight, Apgar score and delivery mode between the two groups of neonates, $P>0.05$. See [Table 1].

The time for PS application in the treatment group is $16(8$, 30) h, the length of hospital stay, the duration of mechanical ventilatory support and CPAP are longer than those in the control group $(\mathrm{P}<0.05)$, the incidence of ventilatorassociated pneumonia and hospitalization expenses are higher than those in the control group $(\mathrm{P}<0.05)$, and also the highest OI is obviously higher in the PS group, which are statistically significant. The duration of oxygen inhalation via nasal prongs, NO inhalation, the incidence of pulmonary air leak, pulmonary hemorrhage and pulmonary hypertension between the two groups have no statistical significance. For prognosis, 75 of 89 in the treatment group are cured or improved and 14 are given up or dead; while 62 of 77 in the control group are cured or improved and 15 are given up or dead, which has no statistical significance between the two groups $(\mathrm{P}=0.527)$, See [Table 2].

\section{DISCUSSION}

It is discovered worldwide [7,8] that morbidity of RDS for late premature infants and term infants has increased gradually in recent years due to the increased proportion of caesarean that is nonmedical indication. Domestic research [9] shows that its morbidity takes up $19 \%$ in the respiratory system diseases of late premature infants, so more and more attention is paid on RDS of (near) full-term infants. Different from early premature infants, RDS of (near) fullterm infants[10,11] mainly result from secondary PS deficiency caused by inhalation of meconium, pneumonia, wet lung and pulmonary hemorrhage. Besides, its clinical manifestation and reaction to treatment of PS are different from RDS of early premature infants; therefore, there is still no consensus on whether PS could be used to treat RDS of (near) full-term infants. Domestic multicenter survey [12] showed that time for applying ventilator to assist respiration for RDS of late premature infants and full-term infants is late, oxygenation condition and PS application effect are poor and complications such as pulmonary air leak and PPHN are easy to occur. It is discovered by Chengyun $\mathrm{Z}$ [13] that PS is effective in treatment of RDS of premature infants but less effective for RDS of (near) full-term newborn. Hence, they claim that mechanical ventilation and removal of primary disease are the main treatment methods

Identify applicable sponsor/s here. (sponsors) for RDS of (near) full-term newborn, and high frequency oscillatory ventilation can be used when necessary. The retrospective analysis of 4 randomized controlled trials, applying PS to treat inhalation of meconium of (near) fullterm newborn conducted by El Shahed AI[14] indicates that the degree of respiratory distress and application of ECMO can be reduced by applying PS, however, the duration of ventilator application, aerobic time, pulmonary air leak, BPD, intracranial hemorrhage and the time for discharge with oxygen are not reduced.

Retrospective analysis of 166 late premature infants or full-term infants with RDS conducted in this center found that 144 are caesarean-delivered babies, accounting for $86.7 \%$, which indicates that caesarean, especially elective csection without initiation of uterine contraction, is a main factor for respiratory distress patients whose gestational age is over 34 weeks. Analysis demonstrates that there is no obvious difference in the morbidity of NO inhalation, pulmonary air leak, pulmonary hypertension and pulmonary hemorrhage between the two groups and also no obvious difference in prognosis of patients in the PS group. Besides, the duration of ventilatory support, CPAP and oxygeninhaling time are obviously longer than those in the control group, the morbidity of ventilator-associated pneumonia and hospitalization expenses are obviously higher and length of hospital stay is obviously longer than those in the control group, indicating that effect of PS for RDS of (near) fullterm newborn is not as effective as for early premature infants.

\begin{tabular}{|c|c|c|c|c|c|c|c|c|c|c|}
\hline \multirow[t]{2}{*}{ Group } & \multirow{2}{*}{$\begin{array}{c}\text { Avera } \\
\text { ge } \\
\text { gestat } \\
\text { ional } \\
\text { age } \\
\text { [week } \\
\text { s] } \\
\end{array}$} & \multicolumn{2}{|c|}{ Gender } & $\begin{array}{c}\text { Polye } \\
\text { mbryo } \\
\text { ny }\end{array}$ & \multirow{2}{*}{$\begin{array}{c}\text { Birt } \\
\text { h } \\
\text { wei } \\
\text { ght } \\
{[g]}\end{array}$} & \multicolumn{3}{|c|}{ Apgar score } & \multicolumn{2}{|c|}{$\begin{array}{l}\text { Delivery } \\
\text { mode }\end{array}$} \\
\hline & & Мa & Female & $\begin{array}{ll}0 & \\
& \mathrm{O} \\
\mathrm{t} & \mathrm{nc} \\
\mathrm{i} & \mathrm{e} \\
\mathrm{m} & \\
\mathrm{e} & \\
\end{array}$ & & $\begin{array}{l}0 \sim \\
3 \\
\mathrm{sc} \\
\text { or } \\
\text { es }\end{array}$ & $\begin{array}{c}4 \sim \\
7 \\
\text { sc } \\
\text { ore } \\
\text { s }\end{array}$ & $\begin{array}{c}8 \sim \\
10 \\
\mathrm{sc} \\
\text { ore } \\
\mathrm{s}\end{array}$ & $\begin{array}{c}\text { Nat } \\
\text { ural } \\
\text { deli } \\
\text { ver } \\
\text { y }\end{array}$ & $\begin{array}{c}\text { Ces } \\
\text { area } \\
\mathrm{n}\end{array}$ \\
\hline 'S group & $\begin{array}{c}39.0 \\
(36.0,4 \\
0)\end{array}$ & 61 & 28 & $\begin{array}{ll}8 & 3 \\
6 & 3\end{array}$ & $\begin{array}{c}260 \\
0(2 \\
400 \\
, \\
305 \\
0)\end{array}$ & 2 & 24 & 29 & 6 & 79 \\
\hline $\begin{array}{l}\text { Control } \\
\text { group }\end{array}$ & $\begin{array}{c}38.0 \\
(35.2,4 \\
0)\end{array}$ & 5\{ & 19 & $\begin{array}{ll}7 & 2 \\
5 & 2\end{array}$ & $\begin{array}{c}277 \\
5(2 \\
300 \\
, \\
330 \\
0)\end{array}$ & 2 & 14 & 21 & 9 & 65 \\
\hline$\chi^{2 / Z}$ & $-1.58 \mathrm{c}$ & & 0.936 & - & $\begin{array}{c}- \\
0.5 \\
14\end{array}$ & & & & & \\
\hline $\mathrm{P}$ & 0.112 & & 0.333 & $\begin{array}{c}1.000 \\
*\end{array}$ & $\begin{array}{c}0.6 \\
07\end{array}$ & 0.7 & & & & \\
\hline
\end{tabular}


OR PLACEBO GROUP BETWEEN THE TWO GROUPS
TABLE II. COMPARISON OF THE CURATIVE EFFECT OF RDS

be reduced by applying PS. However, because of late application, severe secondary lung injury has occurred before PS application, respiration support time should be prolonged; because the duration of ventilatory support is lengthened, morbidity of ventilator-associated pneumonia is raised, and thus length of hospital stay and hospitalization expenses are increased

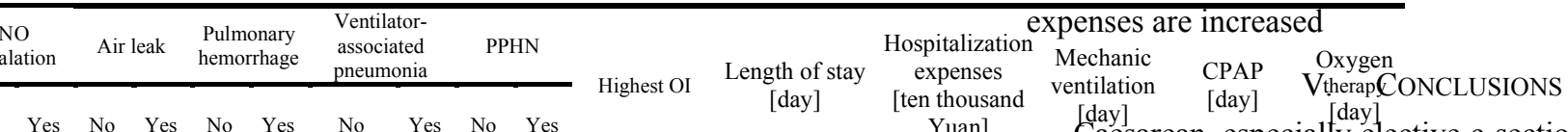

\begin{tabular}{|c|c|c|c|c|c|c|c|c|c|c|c|}
\hline Yes & No & Yes & No & Yes & No & Yes & No & Yes & & 年 & Yuan] \\
\hline 14 & 82 & 7 & 79 & 10 & 63 & 26 & 79 & 10 & $24(22.0,26.5)$ & $20.0(14.0, \quad 27.5)$ & $2.60(1.92,3.51$ \\
\hline 10 & 71 & 6 & 72 & 5 & 68 & 9 & 74 & 3 & $16(12.5,20.0)$ & $15.0(6.5,22.0)$ & $1.30(0.63,1.80$ \\
\hline .251 & & & & & & & & & 9.954 & -3.271 & -7.705 \\
\hline 616 & & & & & & & & & $<0.001$ & 0.001 & $<0.001$ \\
\hline
\end{tabular}

late premature infants and (near) full-term newborn is not as effective as for early premature infants, which is also closely related to medication time, drug dosage and drug use frequency. Few randomized controlled trials on optimal dosage, best medication time and drug use frequency of PS treatment on RDS of (near) full-term newborn were conducted both at home and abroad, thus there is no standard on when to use PS to treat RDS of (near) full-term newborn. Instead, it is decided according to the experience of the clinician. In addition, because of the limitation of economic factors, PS is applied only after ventilator has been applied, high-concentration oxygen has been inhaled and PO2 has been high, OI value has been over 20 and "white lung" has appeared in the X-ray. The highest OI value of patients in the observation group is obviously higher than that in the control group and thus they have statistical differences, indicating that patients in the PS group are more severe than those in the control group, and hypoxia is more serious. Meanwhile, due to the further reduction of secondary PS synthesis, caused by severe hypoxia and acidosis, and also mass consumption, higher ventilator parameter is needed to maintain relatively normal blood oxygen. Since pressure injury, volutrauma and hyperoxic lung injury are caused by mechanical ventilation of high parameter, the duration of ventilatory support and CPAP application time are prolonged, morbidity of ventilator-associated pneumonia is increased, and length of hospital stay is prolonged and thus more economic burden is put on patients. Hence, we believe that the reason why the effect of PS on the treatment of RDS of (near) full-term newborn is not as obvious as for early premature infants is closely related to medication time. It is found that although the highest OI value in the PS group is obviously higher than that in the control group, there is no significant difference in the morbidity of prognosis, NO inhalation, pulmonary air leak, pulmonary hypertension and pulmonary hemorrhage, indicating that PS is effective and further deterioration of disease and occurrence of complications can [day] [day] [day] especially elective c-section without initiation of uterime comtraction is a main factor for respiratory distress

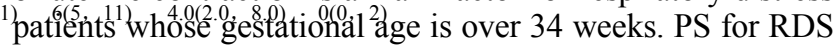
.80 of (mear) fubldtermsnevarborn is not as effective as for early premature infants. It is 1 found that although the highest OI value.oph the PS28group 0is24obviously higher than that in the control group, there is no significant difference in the morbidity of prognosis, NO inhalation, pulmonary air leak, pulmonary hypertension and pulmonary hemorrhage, indicating that PS is effective and further deterioration of disease and occurrence of complications can be reduced by applying PS. PS should be applied for late premature and full-term RDS patients in the early stage. Since this research is only a retrospective analysis, treatment of PS Treatment on RDS of late premature infants and full-term infants, the best medication time and optimal dosage should be further explored by multicenter randomized controlled clinical study.

\section{REFERENCES}

[1] H.L. Halliday, Recent clinical trials of surfactant treatment for neonates. Biol Neonate, vol. 89, 2006, pp.323-329.

[2] V.K.Bhutani, F.W.Bowen and E.M.Sivieri. Postnatal changes in pulmonary mechanics and energetics of infants with respiratory distress syndrome following surfactant treatment. Biol Neonate, vol. 87, 2005,pp.323-331.

[3] R. Soll and E.Ozek,Multiple versus single doses of exogenous surfactant for the prevention or treatment of neonatal respiratory distress syndrome. Cochrane Database Syst Rev, Jan 2009, vol 21 .

[4] A.William, M.D.Engle and the Committee on Fetus and Newborn. Surfactant-replacement therapy for respiratory distress in the preterm and the term neonate. Pediatrics, 2008,pp.419-432.

[5] A.Kribs, F.Pillekamp, C.Hünseler, A.Vierzig and B.Roth, Early administration of surfactant in spontaneous breathing with nCPAP: feasibility and outcome in extremely premature infants (postmenstrual age $</=27$ weeks). Paediatr Anaesth, vol. 17(4),2007,pp.364-369.

[6] Hanzhen.J,Demin.H and Xiji.H, Practice of Neonatology.Edition 3.Beijing :People's Health Publishing House, 2006,pp.421-428.

[7] A.T.Tita, M.B.Landon, C.Y.Spong, Y.Lai, K.J.Leveno, M.W.Varner, et al, Timing of elective repeat cesarean delivery at term and neonatal outcomes. N Engl J Med, 360(2) ,2009:pp.111-120.

[8] Xiujing W, Xundong $\mathrm{Z}$ and Liping S,Retrospective analysis of elective caesarean section and respiratory distress syndrome in the term neonates. Chin J Pediatr, 47(9),2009,pp.658-661.

[9] Ma X, Huang C and Lou S. The clinical outcomes of late preterm infants: a multi-center survey of Zhejiang, China. J Perinat Med, 37(6), 2009,695-699. 
[10] Gouyon JB, Ribakovsky C and Ferdynus C. Severe respiratory disorders in term neonates. Paediatr Perinat Epidemiol, $22(1), 2008,22-30$.

[11] Consortium on Safe Labor, Hibbard JU and Wilkins. Respiratory morbidity in late preterm births. JAMA, 304(4),2010,pp.419-425.

[12] An.C, Liping.S and Jiyan.Z, Clinical characteristics and outcollle\$of respiratory distress syndrome in term and late-preterm neonates. Chin J Pediatr, 46 (9) ,2008,pp.654-657.
[13] Chengyun Z, Jianli Y and Dan W. Clinical analysis of respiratory distress syndrome between preterm, late preterm and term infants. Medical Information Medicine \& Surgery , 22 (8) ,2009,pp.718-719.

[14] El Shahed AI, Dargaville P, Ohlsson A and Soll RF. Surfactant for meconium aspiration syndrome in full term/near term infants. Cochrane Database Syst Rev, 18(3), 2007. 